\title{
EDUCAÇÃO DO CAMPO E INCLUSÃO DE ESTUDANTES COM DEFICIÊNCIA: PERCEPÇÕES E PRÁTICAS DOCENTES
}

\author{
Klayton Santana PORTO \\ Maria José Oliveira DUBOC ${ }^{2}$ \\ Solange Lucas RIBEIRO ${ }^{3}$
}

\begin{abstract}
Resumo
Este estudo tem como objetivo analisar as práticas docentes desenvolvidas no processo de inclusão de estudantes com deficiência, em uma escola do campo de Feira de Santana-BA. Foi realizado um estudo de caso, de natureza qualitativa, cujos dados foram coletados por meio de entrevistas semiestruturadas, realizadas com três professores desta escola, que trabalham com estudantes com deficiência. Dentre os principais resultados encontrados, destacamos que, apesar dos estudantes com deficiência terem o acesso à escola garantido por lei, a Educação Inclusiva ainda não se efetivou na escola do campo investigada. Os dados evidenciam que é necessário um maior investimento por parte da esfera pública, tanto no que se refere à infraestrutura da escola, a formação de professores, como a acessibilidade, em suas várias dimensões.
\end{abstract}

Palavras-chave: Práticas docentes. Estudantes com deficiência. Escola do campo.

\footnotetext{
${ }^{1}$ Doutor e mestre em Ensino, Filosofia e História das Ciências pela Universidade Federal da Bahia. Docente do Curso de Licenciatura em Educação do Campo com habilitações em Ciências da Natureza e Matemática e Coordenador do Curso de Pós-Graduação Lato Sensu em Ensino de Ciências nos anos finais do Ensino Fundamental - Ciência 10! da Universidade Federal do Recôncavo da Bahia. Membro do Grupo de Estudo e Pesquisa em Educação Especial (GEPEE/UEFS/CNPq) e líder do Grupo de Estudos e Pesquisa em Ensino de Ciências e Formação de Professores (GEPECFP/UFRB/CNPq). ORCID: https://orcid.org/0000-0003-4024-6737.

E-mail: klayton@ufrb.edu.br.

${ }^{2}$ Doutora em Educação pela Universidade del Mar. Docente do Curso de Pedagogia da Universidade Estadual de Feira de Santana. Líder do Grupo de Estudo e Pesquisa em Educação Especial (GEPEE/UEFS/CNPq). ORCID: https://orcid.org0000-0003-2800-9843.

E-mail: mariaduboc2016@gmail.com.

${ }^{3}$ Doutora em Educação pela Universidade del Mar. Docente permanente do Mestrado em Educação (PPGE) e do Curso de Pedagogia da Universidade Estadual de Feira de Santana. Vice-líder do Grupo de Estudo e Pesquisa em Educação Especial (GEPEE/UEFS/CNPq). ORCID: https://orcid.org0000-0002-2941-283X.

E-mail: solucasr@hotmail.com.
} 


\title{
RURAL EDUCATION AND INCLUSION OF DISABLED STUDENTS: TEACHING PERCEPTIONS AND PRACTICES
}

\author{
Klayton Santana PORTO \\ Maria José Oliveira DUBOC \\ Solange Lucas RIBEIRO
}

\begin{abstract}
This study aims to analyze the pedagogical practices of including students with disabilities developed by teachers of a rural school in Feira de Santana-BA. The data come from a case of study of qualitative nature, collected through semi-structured interviews with three teachers from that school, who work with students with disabilities. Among the main results found, we highlight that, although students with disabilities have access to school guaranteed by law, Inclusive Education has not yet taken place in the investigated rural school. The data show that greater investment by the public sphere is necessary, both in terms of school infrastructure, teacher training, and accessibility, in its various dimensions.
\end{abstract}

Keywords: Teaching Practices. Disabled Students. Rural School. 


\title{
EDUCACIÓN RURAL E INCLUSIÓN DE ESTUDIANTES CON DISCAPACIDAD: PERCEPCIONES Y PRÁCTICAS DOCENTES
}

\author{
Klayton Santana PORTO \\ Maria José Oliveira DUBOC \\ Solange Lucas RIBEIRO
}

\begin{abstract}
Resumen
Este estudio tiene como objetivo analizar las prácticas docentes desarrolladas en el proceso de inclusión de estudiantes con discapacidad, en una escuela rural de Feira de Santana-BA. Se realizó un estudio de caso cualitativo, cuyos datos fueron recogidos a través de entrevistas semi estructuradas, realizadas con tres docentes de esta escuela, que trabajan con estudiantes con discapacidad. Entre los principales resultados encontrados, destacamos que, si bien los estudiantes con discapacidad tienen acceso a la escuela garantizado por ley, la Educación Inclusiva aún no ha sido efectiva en la escuela rural investigada. Los datos muestran que es necesaria una mayor inversión de la esfera pública, tanto en infraestructura escolar, formación docente y accesibilidad en sus diversas dimensiones.
\end{abstract}

Palabras-clave: Prácticas Docentes. Estudiantes Discapacitados. Escuela Rural. 


\section{Introdução}

A inclusão de pessoas com deficiência nas escolas regulares faz parte das políticas de Educação Inclusiva, instituídas no país nas últimas décadas. Tais políticas buscam garantir que a escola seja um espaço onde todos aprendam, independentemente de suas especificidades. Nesse sentido, devem estender-se à Educação do Campo, uma modalidade educacional que é destinada à população rural, agricultores familiares, extrativistas, pescadores artesanais, ribeirinhos, quilombolas, caiçaras, indígenas, dentre outros (BRASIL, 2010), contemplando também as pessoas com deficiência, que são atendidas nas escolas do campo.

Caldart (2002) afirma que a Educação do Campo não se restringe à educação formal e à escola, embora estas tenham sido elementos marcantes na luta deste movimento, ela vai além, ao mostrar o descaso com as escolas do campo e fomentar a construção de um projeto educativo que dialogue com a realidade mais ampla onde estão inseridas. De tal forma que, a questão do campo é necessariamente a contestação sobre o trabalho no campo, que está vinculada à extensão da cultura, às relações sociais e aos processos produtivos da experiência social, que não ocorrem de forma igualitária no campo, demarcando a necessidade de uma compreensão de educação profissional e da agricultura campesina.

Neste sentido, Arroyo (2006) destaca que os movimentos sociais do campo podem contribuir para dinamizar a escola, fazendo com que esta leve em consideração a realidade dos sujeitos do campo, a partir de suas especificidades e culturas. O intuito da Educação do Campo é oferecer uma educação escolar, associada ao conhecimento e à cultura do campo, que busca desenvolver ações coletivas com a comunidade escolar, numa perspectiva de qualificar o processo de ensino e aprendizagem.

Nota-se, por sua vez, que a presença de alunos com deficiência nas escolas regulares vem aumentando nos últimos anos, de acordo com os dados do Ministério da Educação (MEC). Segundo o Censo de Educação Básica, no ano de 2016, o número de alunos com deficiência, matriculados na educação básica, foi igual a 751.065; já no ano de 2017 esse número correspondeu a 827.243 estudantes. Isso mostra que houve um aumento do número de matrículas de alunos com deficiência nas escolas da rede básica, acompanhado do aumento do índice de inclusão de alunos com deficiência em classes regulares, passando de 85,5\% em 2013, para 90,9\% no ano de 2017.

No entanto, cabe ressaltar que a maior parte desses estudantes não conta com o atendimento educacional especializado (AEE), posto que somente $40,1 \%$ destes conseguem ter acesso a tal atendimento (BRASIL, 2017), o que contraria o estabelecido nos documentos oficiais, como é o 
caso do Plano Nacional de Educação (2014-2024), que preconiza na meta 4 a garantia da oferta de Educação Inclusiva por meio da promoção de articulação entre o ensino regular e o AEE.

Por sua vez, apesar do aumento da matrícula de estudantes com deficiência, não houve mudanças significativas, na grande maioria das escolas, no que se refere à estrutura arquitetônica e pedagógica. Resulta, assim, que muitos estudantes não têm acesso às condições essenciais ao seu desenvolvimento, o que não se constituem responsabilidade exclusiva do professor ou do diretor, mas sim do poder público e de toda comunidade escolar.

Para reverter este quando, é necessário que as barreiras, nas dimensões arquitetônicas, físicas, comunicacionais, informacionais, metodológicas, instrumentais e programáticas, sejam rompidas, pois aos alunos deve ser garantida uma educação que atenda às suas necessidades, de modo que possibilite o seu desenvolvimento educacional e social, conforme preceitua a Educação Inclusiva.

Ressaltamos, deste modo, a importância de se ter um olhar para as práticas docentes voltadas para a inclusão de alunos com deficiência, de modo que sejam propiciadas condições para que estes tenham garantidas as condições de aprendizagem. A partir destas reflexões, elegemos a seguinte questão central para investigação: Quais as práticas docentes desenvolvidas no processo de inclusão de alunos com deficiência em uma escola do campo? Assim, o objetivo geral deste estudo foi analisar as práticas docentes desenvolvidas no processo de inclusão de alunos com deficiência, em uma escola do campo de Feira de Santana-BA. Especificamente, buscamos compreender as percepções dos professores acerca do processo de inclusão de alunos com deficiência; identificar as dificuldades com que os professores se deparam em suas práticas, ao trabalhar com alunos com deficiência no contexto investigado e, por fim, analisar as condições de acessibilidade que permeiam as práticas docentes desenvolvidas no processo de inclusão destes estudantes.

Assim, espera-se que este estudo possa contribuir para uma compreensão mais aprofundada sobre a inclusão de alunos com defíciência na Educação do Campo, além de possibilitar outras discussões acerca da inclusão educacional, que possam trazer elementos contributivos para uma prática docente inclusiva.

\section{A Educação do Campo e a inclusão de alunos com deficiência}

A Educação do Campo surgiu primeiramente com a expressão “Educação Básica do Campo”, na “I Conferência Nacional por uma Educação Básica do Campo,” realizada no estado de Goiás em 1998. Somente passou a ser denominada de Educação do Campo, a partir das 
discussões empreendidas no Seminário Nacional, realizado em Brasília em 2002, reafirmando-se na II Conferência Nacional no ano de 2004 (CALDART, 2012).

No entanto, pode-se afirmar que a Educação do Campo nasceu a partir destas discussões e dos anseios dos movimentos sociais, que lutavam por uma educação básica voltada para os sujeitos do campo que, por sua vez, fora esquecida pelo Estado. Os protagonistas destes movimentos eram trabalhadores do campo, que se viram ameaçados pelos grandes latifundiários, pelo agronegócio; e, também, eram formados por frentes sindicais do campo. Desse modo, esses segmentos lutavam para trazer as Políticas Públicas para o contexto do campo.

Compreende-se que a Educação do Campo tem relação com a cultura, com valores, com o jeito de produzir, com a formação do trabalho e para a participação social, como ressalta Caldart (2012). Por conseguinte, busca valorizar e reafirmar a identidade do homem do campo, trazendo para a sala de aula a realidade vivenciada pelos alunos, fazendo com que estes sejam protagonistas de suas próprias histórias. Essa ação pressupõe a garantia do direito à educação no e do campo ${ }^{4}$.

Neste contexto, as Diretrizes Operacionais para a Educação Básica nas Escolas do Campo, instituídas pela Resolução, CNE/CEB 1, de 3 de abril de 2002, destacam que:

A identidade da escola do campo é definida pela sua vinculação às questões inerentes à sua realidade, ancorando-se na temporalidade e saberes próprios dos estudantes, na memória coletiva que sinaliza frutos, na rede de ciências e tecnologia disponível na sociedade e nos movimentos sociais em defesa de projetos que associem as soluções exigidas por essas questões à qualidade social da vida coletiva no país (BRASIL, 2013. p.282).

Esses aspectos se constituem num conjunto de princípios e procedimentos que visam adequar o projeto institucional das escolas do campo às Diretrizes Curriculares Nacionais. Em seus artigos, essa legislação estabelece os indicadores de qualidade para as escolas do Campo e a necessidade de afirmação identitária da escola. Em seu Artigo $2^{\circ}$, as Diretrizes ainda definem como deve ser o projeto institucional, as propostas pedagógicas e curriculares, o calendário escolar, os mecanismos de gestão democrática, o exercício da docência, a política de formação profissional, o financiamento da educação e as atribuições do Poder Público, para com a universalização do acesso educacional às populações do campo.

O processo de repensar e construir uma Educação do Campo é uma oportunidade de estabelecer interface com a Educação Inclusiva, que tem como imperativo ampliar a participação de todos os estudantes nos estabelecimentos de ensino regular, especialmente aqueles grupos sociais

\footnotetext{
${ }^{4}$ Segundo Caldart (2004, p.149-150): “no: o povo tem direito a ser educado onde vive; do: o povo tem direito a uma educação pensada desde o seu lugar e com a sua participação, vinculada à sua cultura e às suas necessidades humanas e sociais”.
} 
historicamente excluídos da escola, através de uma abordagem voltada para o sujeito e suas singularidades, tendo como objetivos o seu crescimento, satisfação pessoal e inserção social.

O que está sendo construído como Educação do Campo no Brasil, talvez seja a busca por condições dignas de se viver em coletividade e com mais humanismo, em detrimento de interesses da sociedade individualista contemporânea. Uma maneira de viver que inclua verdadeiramente o outro no viver, na qualidade das benesses produzidas pela humanidade, e não a divisão somente da pobreza e das sobras da produção da cultura humana, de alimentação, de moradia, de conhecimento científico, da tecnologia e do desenvolvimento econômico.

Nesse mote, ressaltamos que a escola do campo não pode ser um modelo distorcido da escola da cidade, ou um modelo menor quanto aos processos educacionais discutidos pela teoria pedagógica. Em suma, a escola do campo deve preconizar o desenvolvimento do fazer e do ser coletivo e um saber científico que vem se consolidando pelas lutas dos camponeses e intelectuais orgânicos compromissados com a efetivação de dimensões sociopolítica e cultural de seu currículo.

São, pois, muitos os desafios a serem discutidos, o que remete à busca por uma Educação no e do Campo e as lutas por uma Educação Inclusiva que tenham qualidade, visando um projeto de educação para uma sociedade humanizada. O empenho na construção de uma educação voltada para escolas públicas inclusivas no campo poderá abrir caminho para situações melhores de vida no que se refere a um modelo mais justo e igualitário para todos sujeitos que vivem no campo.

No entanto, a Educação Inclusiva no campo é um desafio, posto que se evidencia por uma necessidade de analisar coletivamente a implantação e efetivação das políticas do campo, na sua relação com a inclusão das pessoas com deficiência, necessidades educacionais especiais, transtornos globais do desenvolvimento, altas habilidades/superdotação, dentre outros.

O documento que preceitua a Política Nacional de Educação Especial na Perspectiva da Educação Inclusiva (2008) esclarece que

O movimento mundial pela educação inclusiva é uma ação política, cultural, social e pedagógica, desencadeada em defesa do direito de todos os alunos de estarem juntos, aprendendo e participando, sem nenhum tipo de discriminação. A Educação Inclusiva constitui um paradigma educacional fundamentado na concepção de direitos humanos, que conjuga igualdade e diferença como valores indissociáveis, e que avança em relação à ideia de equidade formal ao contextualizar as circunstâncias históricas da produção da exclusão dentro e fora da escola (BRASIL. 2008. p.1).

O referido documento dialoga com a organização do trabalho pedagógico das escolas do campo, com vistas à efetivação da política inclusiva, uma vez que a inclusão na Educação do Campo se insere, assim, em uma dimensão em que se articula diferença e diversidade, entendendo 
que diferença não significa desigualdade, mas um alargamento da riqueza cultural que demarca cada ser humano e de cada grupo que vive no campo. Nas palavras de Candau (2011, p.128), “o que estamos querendo trabalhar é, ao mesmo tempo, negar a padronização e também lutar contra todas as formas de desigualdade e discriminação presentes na sociedade”. A Constituição do Brasil, em seu Art. 205, assegura a educação como um direito de todos, visando "o pleno desenvolvimento da pessoa, seu preparo para o exercício da cidadania e sua qualificação para o trabalho”, o que nos faz aproximar o texto legal da ideia de uma escola capaz de atender as mais diferentes pessoas.

Assim como o processo de inclusão de alunos com deficiência, em espaços escolares, a valorização destes indivíduos também perpassa pela mudança do modelo pedagógico e metodológico, de modo que seja assegurado o seu direito à aprendizagem. Como salienta Ribeiro (2017):

Esse direito de estar incluído nas instituições educacionais e de aprender é assegurado pelo ordenamento jurídico brasileiro desde a Carta Magna até os documentos que compõem o ordenamento infraconstitucional. Tal direito está amparado também em acordos internacionais, a exemplo, das Declarações de Jomtien, 1990, e de Salamanca, 1994, além, da Convenção Internacional dos Direitos da Pessoa com Deficiência de 2007, resultantes de fóruns mundiais de discussão sobre essa temática, das quais o Brasil foi signatário (RIBEIRO, 2017, p.25).

Todos os alunos com deficiência têm o direto de participar da vida escolar e social, de fazer suas próprias escolhas. Ao considerar este entendimento, deve-se ter o entendimento que o processo pelo qual se analisa e se implementa a inclusão nas escolas do campo tem a ver com uma conjugação de fatores, visto que, para além da presença de estudantes com deficiência, nessas escolas, ainda é preciso promover diversas melhorias em sua infraestrutura, para melhorar a acessibilidade destes estudantes, além da necessidade de uma melhor formação inicial e continuada destes educadores e de uma melhoria de suas práticas, voltadas para a inclusão destes estudantes com deficiência. De modo que essas práticas sejam de fato pedagógicas, ou seja, permeadas pelos processos formativos e expectativas destes professores, pelos espaços e tempos escolares e pela organização do trabalho pedagógico destas escolas do campo (FRANCO, 2016) e não apenas se constituam como práticas docentes.

Assim, para a inclusão de alunos com deficiência nas escolas do campo, as questões pedagógicas demandam uma estrutura apropriada. Nesse sentido, se insere a questão da acessibilidade nas escolas do campo, abordada na seção seguinte. 


\section{A inclusão e a (in)acessibilidade da escola do campo}

Na tessitura de uma Educação Inclusiva, entende-se que o binômio acessibilidade/inclusão é indissociável (RIBEIRO, 2011). Ressalta-se, deste modo, que a acessibilidade, antes voltada apenas para a supressão de barreiras arquitetônicas, ampliou seu conceito, passando a englobar dimensões anteriormente não contempladas, visando a eliminação de quaisquer barreiras físico-arquitetônicas ou psicossociais, que possam obstaculizar a inclusão educacional. Entende-se que as deficiências físicas, sensoriais ou mentais não, necessariamente, incapacitam o sujeito para a vida, mas somente representam limitações para estes estudantes, em decorrência das inadequações do ambiente. Por conseguinte, a preocupação deve voltar-se para a eliminação das muitas barreiras que permeiam os espaços escolares, ou seja, a acessibilidade.

Nesse delineamento, a acessibilidade é aqui entendida em uma concepção mais ampla que transcende a questão físico-arquitetônica. É condição acessível aos lugares, às pessoas, aos serviços, dentre outros. É a possibilidade de interagir com o ambiente de forma digna e segura, com o máximo de autonomia possível, mesmo que as pessoas tenham comprometimentos acentuados (RIBEIRO, 2011), que, por conseguinte, contempla diversas dimensões. Sassaki (2007) admite seis: arquitetônica, comunicacional, metodológica, instrumental, programática e atitudinal. Essa última é relevante, pois pressupõe um contexto social livre de estigmas, preconceitos e discriminações, importantes para a Educação do Campo, de modo que se perceba claramente que as demais estão imbricadas à essa.

Entretanto, apesar da legislação em vigor voltar-se para a eliminação de barreiras e à inclusão escolar dos alunos com deficiência, a realidade das escolas do campo está muito distante do que estabelece a Lei Brasileira de Inclusão (LBI nº 13.146/2015), que considera barreira.

Qualquer entrave, obstáculo, atitude ou comportamento que limite ou impeça a participação social da pessoa, bem como o gozo, a fruição e o exercício de seus direitos à acessibilidade, à liberdade de movimento e de expressão, à comunicação, ao acesso à informação, à compreensão, à circulação com segurança, entre outros (BRASIL, 2015, p.34).

Assim, a inacessibilidade verificada nas escolas é preocupante e, considerando as escolas do campo, as adversidades ainda se acentuam, visto que as carências da escola pública são particularmente acentuadas no campo, caracterizando-se, muitas vezes, pela insuficiência de professores qualificados, pela precariedade das instalações e por uma organização curricular descontextualizada do cotidiano dos povos do campo. 
No que diz respeito ao conforto ambiental, a inobservância é perceptível, pois muitas destas escolas do campo possuem uma única sala, de classe multisseriada, sem iluminação, ventilação, mobiliário e recursos didáticos adequados para atender às especificidades dos estudantes do campo, sobretudo, no atendimento dos alunos com deficiência. Ademais, o acesso, via de regra, é muito difícil, não só pelas distâncias, como também pela precariedade dos transportes, que expõem alunos e professores a riscos e humilhações constantes. No entanto, embora o quadro seja pouco animador, é passível de mudanças.

\section{Percurso metodológico}

A abordagem metodológica desta pesquisa foi qualitativa, utilizando-se do método empírico do tipo estudo de caso. De acordo com Johnson e Christensen (2012), a pesquisa qualitativa é um tipo de pesquisa que não requer o uso de métodos e técnicas estatísticas, pois o ambiente natural é fonte direta para coleta de dados, e o pesquisador é o instrumento-chave. Por haver uma relação dinâmica entre o mundo real e o sujeito, isto é, um vínculo indissociável entre o mundo objetivo e a subjetividade do sujeito, sua interpretação não pode ser traduzida em números.

Além disso, a realidade investigada retrata o processo de inclusão de alunos com deficiência que se desenvolve em uma escola do campo, um ambiente que, geralmente, já contabiliza alguns problemas, que resultam dos processos historicamente constituídos. Já o estudo de caso é definido por Alves-Mazzotti (2002) como um tipo de pesquisa que se destina à análise de um caso particular, porém representativo dentro de um universo. O estudo de caso, nesta pesquisa, justifica-se, por investigar e retratar um contexto específico e delimitado, em uma busca circunstanciada de informações.

A pesquisa foi desenvolvida com três professores de uma escola do campo da Rede Municipal de Educação de Feira de Santana - BA, que trabalham com alunos com deficiência visual, física e intelectual, matriculados nos anos finais do Ensino Fundamental. A escolha deste lócus, se deu por ser esta uma escola do campo que possui Sala de Recursos Multifuncionais (SRM), com profissionais com formação na área da Educação Inclusiva, que objetivam oferecer atendimento complementar e/ou suplementar aos alunos com deficiência.

Como instrumento de coleta de dados, foram realizadas entrevistas semiestruturadas com os professores. Para a análise das entrevistas, foi realizada a Análise Textual Discursiva (ATD) que, de acordo com Moraes e Galiazzi (2011), representa um rigoroso processo, sistemático e não neutro, cujas análises e interpretações desenvolvidas pelos pesquisadores são carregadas de uma 
subjetividade que permeia os discursos do investigador, suas concepções de mundo, suas ideias preconizadas, expandidas e reelaboradas no decorrer do processo de construção do conhecimento.

A ATD foi delineada a partir das seguintes etapas: (i) organização do corpus da análise, (ii) unitarização dos elementos de significado, (iii) definição das categorias e (iv) produção do metatexto. A partir desta análise, emergiram duas categorias analíticas, a saber: (I) percepções de inclusão de alunos com deficiência e práticas docentes e (II) a (in)acessibilidade da escola do campo: possíveis implicações à inclusão de alunos com deficiência.

Assim, foi possível analisar as percepções dos professores sobre a relevância de suas práticas docentes, no processo de ensino e aprendizagem de estudantes com deficiência, no ambiente desta escola do campo.

\section{Percepções e práticas docentes sobre a inclusão de alunos com deficiência na Educação do Campo: o que nos revela a pesquisa}

No intuito de compreender as práticas docentes desenvolvidas no processo de inclusão de alunos com deficiência em uma escola do campo, foram entrevistados três professores, denominados de PA, PB e PC. Estes professores trabalham com estudantes com deficiência visual, física e intelectual, nesta escola. O professor PA tem formação inicial na área de Ciências da Natureza, PB na área de Linguagens e PC com formação inicial em Ciências Humanas. Dentre estes, PC atua na SRM da escola e PA e PB atuam em classes comuns.

\section{Percepções sobre a inclusão de alunos com deficiência e práticas docentes}

Como mencionado anteriormente, a presença de alunos com deficiência requer que os professores mudem seu trabalho. Isto exige uma preparação maior e mais elaborada, direcionada aos conteúdos, atividades diferenciadas, adaptação de materiais e flexibilização curricular, para garantir o atendimento às características e necessidades desses alunos, possibilitando-lhes participar e aprender juntamente com seus colegas.

Entretanto, muitos desses professores não sabem o que fazer, diante dos alunos com deficiência. Neste sentido, Matos (2015, p.103) ressalta que:

A presença de estudantes com deficiência em sala de aula do ensino regular exige mudanças na organização do trabalho pedagógico do docente à medida que se torna necessário desenvolver ações para garantir a participação dos mesmos no processo de ensino e aprendizagem. 
Depreende-se da citação anterior dois elementos estritamente articulados para a inclusão de estudantes com deficiência, em uma escola do campo: a organização do trabalho pedagógico e as ações a serem desenvolvidas, na perspectiva de assegurar que as práticas inclusivas desenvolvidas com estes estudantes sejam de fato pedagógicas. Franco (2006, p. 537-538) ressalta que práticas pedagógicas:

se realizam para organizar/potencializar/interpretar as intencionalidades de um projeto educativo. Argumenta-se a favor de outra epistemologia da Pedagogia: uma epistemologia crítico-emancipatória, que considera ser a Pedagogia uma prática social conduzida por um pensamento reflexivo crítico do que pode ser a prática educativa.

A prática pedagógica é uma prática intencional de ensino e aprendizagem, que não se reduz às metodologias de estudar e de aprender ou à questão didática. Nesta concepção, o processo educacional se constitui enquanto prática social e o conhecimento é compreendido como produção histórica e social, situado numa relação dialética entre conteúdo e forma, teoria e prática, levando em consideração perspectivas interdisciplinares. Neste sentido, Fernandes (1999) complementa que esse tipo de relação pedagógica não é assimétrico, na medida em que professor e aluno ensinam e aprendem, construindo e reconstruindo o conhecimento de forma colaborativa.

Outra questão, que se entremeia nessa discussão sobre a prática pedagógica, é a formação docente, inicial e continuada, de qualidade, para todos os níveis de educação. Essa formação deve ser um compromisso público de Estado, para que as propostas "não fiquem somente no papel”, como é recorrente na fala dos três professores.

Acerca das dificuldades que enfrentam no dia a dia, os depoimentos dos professores convergem sempre para a questão do material didático, da formação e do currículo, conforme os fragmentos a seguir:

Material didático inadequado para sua necessidade. Impossibilidade de fazer um atendimento específico em função das demandas do conteúdo (PA).

Não me senti plenamente capacitado para lidar com alunos com deficiência. Além disso, percebo que estes estudantes não conseguem acompanhar seus colegas, aprender junto com os demais. Porém não me sinto preparado para lidar com estas situações. Falta de assistência de Secretaria de Educação, uma vez que cursos são ofertados, porém estes cursos, em sua maioria, só são ofertados por conta das exigências legais do MEC (PB).

Compreensão do conteúdo ministrado, tempo insuficiente para realização das atividades propostas, escassez de interação com os seus pares na turma, material didático inadequado para sua necessidade. Inexistência de apoio institucional (PC).

Diante das condições inadequadas de trabalho, os professores mostram insegurança e ressaltam as fragilidades da formação inicial, sobretudo, no que se refere à Educação Inclusiva. Isso é latente, visto que os cursos de licenciatura, em geral, não promoveram reformas curriculares 
significativas, que de fato contemplem a dimensão inclusiva. Muitos destes cursos apenas introduzem conteúdos, pertinentes à Educação Inclusiva, de forma bem fragmentada, em alguns componentes curriculares, somente para atender às exigências do MEC, sem que seja realizado um mínimo de esforço para se reduzir a dicotomia existente entre a teoria e a prática, no âmbito deste processo formativo (FERREIRA; PORTO, 2020). Por sua vez, a formação continuada, embora PC afirme que são disponibilizados materiais de estudo e orientação para os professores, as lacunas permanecem, tanto na formação destes professores quanto em suas práticas docentes, voltadas para a inclusão de alunos com deficiência.

Outras dificuldades são sinalizadas por PC, professora da SRM:

Uma das dificuldades que encontrei foi a de convencer a própria família que aquele sujeito era capaz de pensar e produzir conhecimento. Em seguida, trabalhar arduamente com a turma para que percebessem que todos, inclusive os estudantes com deficiência, apresentavam diferentes maneiras de aprender e que por isso, deveria haver ajuda mútua. Outra dificuldade foi na adaptação de material e o uso do tempo didático. A escola pública "perde" muito tempo com cópias por não ter material xerocopiado para todos ou mesmo o livro didático (PC).

Neste relato, a professora destaca como dificuldade o fato de familiares considerarem que o indivíduo com deficiência é incapaz de aprender, de pensar, ou de ter vontade própria, o que implicou em empreender esforços para mudanças destas crenças e valores. Aponta, também, a falta de entendimento dos demais alunos em relação aos que não apresentam o mesmo ritmo de aprendizagem, bem como a insuficiência de uma infraestrutura didático-pedagógica que contribua para a efetividade de seu trabalho.

Nessa perspectiva, ressaltamos que a organização e o funcionamento da escola não viabilizam a efetividade da prática docente voltada para os alunos com deficiência, uma vez que se apresentam com tempos engessados, conteúdos padronizados, recursos insuficientes, professores sem o devido preparo e a falta de apoio de familiares, conforme expressam os depoimentos dos professores.

Por isso, afirma-se que a inclusão dos alunos com deficiência na Educação do Campo exige muita reflexão e implementação de dinâmicas próprias, inerentes ao processo educativo, numa corresponsabilização e envolvimento dos professores, gestores, pessoas e setores intervenientes da comunidade escolar. Desse modo, a inclusão destes estudantes deve partir do entendimento de que a prática pedagógica desenvolvida seja articulada com a teoria, comprometida com a razão de ser do trabalho educativo e pautada em um projeto transformador, que leve em consideração, sobretudo, a dimensão social presente no contexto campesino (FERREIRA; PORTO, 2020). Nesse delineamento, busca-se analisar as alternativas utilizadas pelos professores para superar as dificuldades enfrentadas em suas práticas docentes: 
Formas de avaliação diversificadas (PA).

Tentei elaborar avaliações diversificadas de modo que pudessem contribuir para que estes estudantes com deficiência conseguissem aprender com os seus colegas. [...] Percebo que deu um pouco certo, porém tenho a certeza que não terei condições de saber lidar com os mais diversos tipos de deficiência que os estudantes apresentam no ambiente da escola (PB).

Recursos didáticos adaptados, formas de avaliação diversificadas, metodologia diferenciada, ampliação do tempo para o desenvolvimento das atividades em sala de aula (PC).

Nas respostas, é possível observar que os professores tomam algumas inciativas para melhor atender os estudantes com deficiência, sejam através de avaliações e metodologias diversificadas ou por meio da utilização de recursos didáticos adaptados às especificidades destes estudantes. Nesse quesito, perguntamos aos professores “que mudanças foram realizadas na metodologia, nos recursos didáticos, enfim, nas práticas docentes para o atendimento/desenvolvimento dos alunos com deficiência?” Suas falas nos revelaram que:

Para atendimento das necessidades do aluno utilizei mais vídeos para que o aluno pudesse escutar sobre o conteúdo que estava sendo trabalhado. Também, realiza as atividades de classe sempre em dupla para que o aluno cego tivesse quem fizesse a leitura para ele e com quem discutir sobre a resposta. [...] $O$ aluno conseguiu acompanhar a disciplina sem maiores dificuldades (PA).

Tento melhorar a minha prática enquanto docente, porém o sistema não contribui para que a inclusão e a aprendizagem destes alunos com deficiência ocorram de fato e de direito. Sei que a culpa não é minha, pois tenho boa vontade para rever minha prática, porém sei que minha pouca formação nesta área, o pouco caso e investimento da Secretaria de Educação e o excessivo número de alunos que temos em cada turma funcionam como um grande entrave para a inclusão sair do papel e para que uma escola do campo, como a nossa, realmente possa incluir os estudantes com deficiência (PB).

Quando qualquer aluno demonstra ter dificuldade, procuro rever a metodologia, modifico a rota de trabalho, procuro ouvi-los para saber $e$ conhecer seus interesses, dificuldades e o que foi aprendido. Mesmo quando eu tinha duas turmas, o planejamento era diferenciado para atender as singularidades e a pluralidade da turma. A mediação também era prática constante e formando sempre alunos mediadores para ajudar-me nas atividades. Errei muito, tentando. Mas, a melhor forma de contribuir com o acesso ao currículo escolar é escutando os estudantes, conhecer o que sabem, ver o nível cognitivo que cada um se encontra e propor modalidades organizativas que atendam às necessidades e para que acessem os conhecimentos historicamente acumulados pela humanidade (PC).

Os professores PA e PC, sinalizaram que procuram desenvolver estratégias diferentes com os estudantes com deficiência. Além disso, PC também destacou que costuma ampliar o tempo no desenvolvimento das atividades, o que se constitui uma condição mais fácil de ser realizada, em se tratando da SRM, cujo atendimento comumente ocorre de forma individualizada, diferentemente da 
sala de aula comum que abarca muitos alunos ao mesmo tempo e, ainda, está submetida a uma cronologia previamente determinada. No entanto, ao analisarmos a fala de $\mathrm{PB}$, percebemos que esta estratégia não é utilizada por ele, ao justificar que as condições de trabalho e o número excessivo de alunos em sala de aula não favorecem o desenvolvimento de um trabalho diferenciado com estes estudantes com deficiência.

A utilização de estratégias diversificadas e adaptadas à realidade destes estudantes é importante, uma vez que Sacristán e Pérez Gomez (1998) ressaltam que não se consegue a reconstrução das atitudes, dos conhecimentos e dos modos de atuação dos estudantes, sem considerar as vivências destes, suas experiências de aprendizagem, as relações sociais presentes na escola, em seu entorno e o intercâmbio de ideias que permeiam o contexto da inclusão destes estudantes com deficiência, nesta escola do campo. Apesar de se destacar essa relevância, nas falas dos professores percebe-se, no entanto, que as inciativas e mudanças realizadas em suas práticas docentes ocorrem de forma isolada, com base em uma lógica adaptativa, diante das diferenças nos modos de aprendizagem, que eles identificam no decorrer das ações desenvolvidas. Tais práticas tendem a provocar impactos negativos tanto na inclusão destes estudantes, como em sua aprendizagem.

Ao perguntarmos sobre as possiblidades de aprendizagem que os professores percebiam nestes estudantes, estes responderam:

O aluno com cegueira tem total possibilidade de estudar em uma classe regular com os demais alunos sem deficiência. Ele só precisa de algumas adequações na rotina de sala de aula para que tenha condições de aprender (PA).

Percebo que a matrícula destes estudantes é garantida por lei, porém não vejo investimento pela Secretaria de Educação para garantir que estes estudantes se desenvolvam em sua plenitude. [...] Percebo muita sobrecarga de responsabilidade para nós professores darmos conta para garantir que estes alunos sejam incluídos, que aprendam e se desenvolvam enquanto cidadãos de direitos. Na prática, o professor tem que dar conta sozinho do que a Secretaria não cumpre, não investe e não forma adequadamente o seu quadro de professores $e$ de profissionais da educação. Espero que essa situação mude algum dia. Sobretudo porque aqui estamos nos referindo a uma escola do campo, cujos investimentos são bem mais escassos do que nas escolas da sede (PB).

O estudante com deficiência, por muitas vezes, tem sua matrícula e acesso garantido na escola, mas nem sempre os colegas professores os enxergam com possibilidades de aprender e se desenvolver, por diversas razões. Assim, muitos destes estudantes têm sua aprendizagem negligenciada por acreditarem (professores e por vezes até a família) que não aprendem. Quando há investimento no estudante, adequação da linguagem e das atividades é possível ver avanços significativos (PC).

Em sua fala, PA afirma que o aluno com deficiência visual tem total condição de frequentar uma sala de aula regular, mas o que o impede de aprender são as condições em que se encontra a 
escola, bem como a falta de apoio das instituições externas, tais como MEC, Secretaria de Educação, dentre outras, sem isentar também a responsabilidade do professor. É curioso constatar que há professores, assim como alguns familiares que não acreditam na capacidade de aprender destes estudantes com deficiência. Nas entrelinhas do relato, percebemos que PA faz ressalva apenas ao aluno com deficiência visual, o que nos leva à indagação: os alunos com as demais tipologias de deficiência não têm condições de serem incluídos na escola comum? Destaca-se aqui que todos os alunos têm condições de aprender, desde que lhes sejam oferecidas as condições para isso, pois:

Criar escolas inclusivas requer muito mais que boas intenções, declarações e documentos oficiais, requer que a sociedade, escolas e professores tomem consciência das tensões e organizem condições para criação de escolas inclusivas de qualidade (TOLEDO; MARTINS 2009, p. 4129).

Nessa direção, evidencia-se o depoimento de PC, ao afirmar que “(...) errei muito, tentando. Mas, a melhor forma de contribuir com o acesso ao currículo escolar é escutando os estudantes, conhecer o que sabem, ver o nível cognitivo que cada um se encontra”. Com base nesse caminhar, nessas tentativas e na reflexão continua, defende-se, sim, que é possível modificar a realidade educacional, por meio do desenvolvimento de práticas docentes que contribuam para a inclusão destes estudantes com deficiência nas escolas do campo, de modo que lhes sejam asseguradas condições plenas para a sua aprendizagem.

Nesse contexto, as recorrentes falas dos professores, a todo momento, mencionam a (ir)responsabilidade do poder público, por não assegurar as condições mínimas para a efetividade dos princípios demandados a uma escola do campo inclusiva. De fato, a precariedade das condições de trabalho é acentuada nas escolas do campo, mas não podemos isentar os professores de assumir o protagonismo de sua ação docente, mesmo que não tenham o apoio da esfera pública. Neste sentido, Mantoan (2009) complementa que o processo de inclusão exige da escola novos recursos de ensino e aprendizagem, concebidos a partir de uma mudança de atitudes dos professores e da própria instituição. Para isso, faz-se necessário abandonar o conservadorismo de suas práticas e ir em direção a uma educação que esteja realmente interessada em atender às necessidades de todos os estudantes.

Assim, ressalta-se que a inclusão de estudantes com deficiência na Educação do Campo demanda uma urgente mudança no atual paradigma educacional, precisando mudar o pensamento de toda a escola, no sentido de valorizar o saber construído pelo aluno e que toda a comunidade escolar esteja aberta ao diálogo e às novas concepções de aprendizagem (FERREIRA; PORTO, 2020). É necessário tirar o foco das limitações destes estudantes para poder se concentrar e acreditar em suas potencialidades, de modo que seja, de fato, garantida e empreendida uma Educação do Campo Inclusiva, em todas as suas dimensões. 
Os aspectos mencionados levam a tencionar a cultura historicamente estabelecida, que tende a focar o trabalho educativo exclusivamente no professor e esquece que a escola precisa passar por modificações epistemológicas e estruturais, que reflitam no seu projeto pedagógico. A escola precisa assumir seu papel de educar, a família precisa assumir seu papel de cuidado e o governo as funções assistenciais. Em se tratando das pessoas com deficiência que vivem no campo, é necessário reconhecer que, para além da deficiência, estes são sujeitos participes de um lugar singular que, embora permeado pelo descaso, há inúmeras possibilidades de promover uma formação de qualidade, que lhes garanta o acesso a condições mais dignas de vida.

Neste sentido, Toledo e Martins (2009) complementam que a sala de aula, dependendo de como o professor a conduz, poderá ser um ambiente rico para a inclusão de estudantes com deficiência, desde que sejam consideradas as interações destes com o meio, com os recursos ou instrumentos externos que o sujeito utilizará para a compensação da deficiência. Para isso, o professor deverá estar atento para não se prender às aparentes limitações do estudante e entender que as limitações podem também estar na sua compreensão sobre a deficiência.

Após compreendermos sobre as percepções dos professores desta escola do campo sobre a inclusão de alunos com deficiência e sobre suas práticas docentes, iremos buscar refletir sobre as condições de acessibilidade da escola e suas possíveis implicações na inclusão destes estudantes.

\section{A (in)acessibilidade da escola do campo: possíveis implicações à inclusão de alunos com deficiência}

Entende-se que há uma estreita interface entre acessibilidade e inclusão. Assim, só o acesso não é suficiente, pois é preciso que estejam garantidas as condições de acessibilidade, em suas várias dimensões. Entretanto, observa-se que tais condições ainda se constituem em um aspecto bastante frágil nas escolas, principalmente, nas do campo. Assim, na perspectiva de analisar tais condições, fizemos o seguinte questionamento aos professores: "em termos de acessibilidade, visando a inclusão de estudantes com deficiência, você considera que as condições dessa escola propiciam a participação plena e o processo de aprendizagem desses estudantes?” Os excertos das falas causam preocupações, conforme evidenciam os depoimentos.

O estudante com deficiência, por muitas vezes, tem sua matrícula e acesso garantidos na escola, mas nem sempre os colegas professores os enxergam com possibilidades de aprender e desenvolver, por diversas razões. [...] O que falta na instituição, é o que falta na sociedade, consciência dos direitos destes sujeitos em relação ao conhecimento, ao espaço público, e à plena participação deste como um cidadão comum (PC). 
Falta material adequado, como livros em braile e outros materiais que o aluno possa utilizar para melhor entendimento do conteúdo, já que o toque para ele é de suma importância para aprendizagem do novo (PA).

Falta investimento da Secretaria de Educação. Falta formação adequada e de qualidade para nós professores. Falta boa vontade de alguns colegas em serem sensíveis e lidar com estudantes com deficiência, dentre tantas outras coisas (PB).

Nas respostas foram pontuadas a inacessibilidade aos recursos didáticos, como evidencia PA, aos processos formativos e, também a questão atitudinal, como expressam PC e PB, por parte da Secretaria de Educação do Município, como foi evidenciado nas falas dos professores, o que compreendemos que desencadeia efeitos danosos para o desempenho e a aprendizagem do estudante. A fala de PC, quando se reporta à inclusão dos alunos com deficiência, é preocupante, pois esta adverte que eles “(...) têm sua matrícula e acesso garantidos, na escola, mas nem sempre os colegas professores os enxergam com possibilidades, por diversas razões”. Isso nos faz refletir sobre o preconceito velado e o descrédito nas potencialidades destes estudantes com deficiência. O que se constitui uma barreira psicossocial e uma inacessibilidade atitudinal para estes estudantes. Importa aqui ressaltar, que são as interações com o meio, com os recursos e instrumentos que contribuem para o sujeito compensar a sua deficiência (TOLEDO; MARTINS, 2009).

Essa compreensão nos leva a deduzir que, quando o professor não acredita que o aluno tem potencialidade para aprender, este acaba não se motivando em investir na mediação. Por conseguinte, o não sucesso desse estudante, via de regra, acaba sendo sempre atribuído à sua deficiência e não às práticas docentes, não inclusivas, que este professor desenvolve. Sobre isso, Sanches e Teodoro (2007, p. 113) advertem que:

Se os alunos estão na escola é para fazer aprendizagens, as que forem capazes de fazer com a disponibilização de meios e métodos de que carecem, porque as aprendizagens são um meio de aceder à cidadania. Se não aprendem, é porque não os sabemos ensinar, porque, por vezes, são precisas metodologias diferentes ou códigos de comunicação apropriados, como é o caso do «braile» para os cegos, da comunicação gestual para os surdos ou da aprendizagem multiestruturada para os que têm déficit cognitivo.

A partir dessa reflexão, ressaltamos que não é possível construir uma Educação Inclusiva sem conhecer os estudantes envolvidos, uma vez que precisamos identificar as necessidades e potencialidades destes estudantes, de modo que sejam avaliados para se compreender se de fato estão aprendendo. E se não estiverem aprendendo, deverão ser oportunizadas possibilidades para que estes aprendam, assim como se espera que seus colegas aprendam, para que, de fato, a escola do campo se constitua um ambiente inclusivo. 
Consideramos pertinente também conhecer, na perspectiva dos professores, não só o que já foi feito, mas o que deveria ser feito pela escola, no sentido de favorecê-los no desenvolvimento de uma prática docente inclusiva para os estudantes com deficiência. Eles destacam que:

A psicopedagoga da escola fez acompanhamento durante todo o ano com o aluno, com a família e com os docentes. Disponibilizou material de estudo e orientação para os docentes. Além disso, gestores e coordenadores fizeram o possível para que o aluno fosse bem acolhido e orientou a turma para que esta soubesse lidar com a deficiência apresentada pelo aluno. Acredito que será necessária uma continuidade na formação dos docentes (PA).

A escola busca fazer a parte dela, porém falta uma política efetiva da prefeitura para promover a inclusão de estudantes com deficiência em escolas como a nossa, uma escola do campo que, muitas vezes, vive esquecida de investimentos e de melhores oportunidades para os estudantes, professores, pais e todos envolvidos na comunidade escolar (PB).

Como professora da Sala de Recursos Multifuncionais, busco diálogo constante com meus pares, além de encontros específicos para atender às demandas, dúvidas, reflexão sobre práticas pedagógicas inclusivas. [...] A gestão é essencial para a inclusão, pois dela deve vir a garantia desse direito não negando a matrícula, compreendendo a necessidade de adaptação de atividades, alongamento de tempo específico dos estudantes, realizando reuniões de pais, de professores, deixando acesso livre para o uso dos livros que são enviados pelo MEC e que tratam da inclusão, além de apoio a saída dos professores para formação externa sobre a temática (PC).

Ao analisar esses excertos, pode-se perceber que os professores se referem, basicamente, às várias iniciativas que a escola já desenvolve para promover a inclusão destes estudantes com deficiência, procurando, de certa forma, não só isentá-la com também isentar-se de responsabilidade, pela inacessibilidade aos recursos, metodologias e processos formativos, necessários à Educação Inclusiva no campo, ao tempo em que culpabilizam sempre os segmentos extramuros escolares pela não inclusão destes estudantes na escola do campo investigada.

Os depoimentos anteriores sinalizam problemas diversos, a exemplo de reclamações dos professores quanto a serem obrigados a dar conta sozinhos da inclusão destes estudantes com deficiência; da falta de preparo para que assumam a responsabilidade por esses estudantes; da falta de espaços para discussões importantes que envolvam o planejamento, realização de reuniões pedagógicas, avaliação e o desenvolvimento de mecanismos que atendam às especificidades destes estudantes, dentre outros. Também, algumas expressões utilizadas pelos professores permitem perceber a dimensão da realidade que vivenciam, cujo sistema educacional não fortalece essas escolas do campo, como desabafa PB, acerca da escola investigada, se reportando a ela como "uma escola do campo que, muitas vezes, vive esquecida de investimentos e de melhores oportunidades para os estudantes, os professores, pais e todos envolvidos na comunidade escolar (PB). 
Entretanto, mesmo reconhecendo essas dificuldades, faz-se necessário transcender da denúncia e da queixa para a ação, pois alguns desses entraves podem e devem ser resolvidos pela própria escola, com destaque para o papel do gestor/diretor escolar e professor, a exemplo de materiais didáticos que podem ser construídos e/ou adaptados, pois demandam pouco investimento; da criação de espaços para estudos e troca de experiências, dentre tantas outras possibilidades.

Para tanto, é pertinente destacar que o ambiente escolar, em questão, carece de oportunidades de compartilhamento de experiências entre seus pares e de um projeto pedagógico que contemple, em suas bases, os princípios para que a Educação Inclusiva venha a permear a realidade da vida campesina destes professores e estudantes. No sentido de possibilitar a acessibilidade, em suas múltiplas dimensões, visando propiciar o processo de ensino e aprendizagem a todos os estudantes, independentemente de suas diferenças. Não perdendo o foco de que há todo um conjunto de responsabilidades e deveres para que estes direitos sejam cumpridos.

\section{Considerações finais}

A Educação Inclusiva propõe que os sujeitos que possuem qualquer tipo de deficiência sejam incluídos no ambiente escolar, de modo que lhes sejam garantidos o acesso à educação e o direito de aprender, sem que sofram descriminação, conforme assegura a Legislação. Propõe, ainda, que as escolas estejam preparadas para atender às necessidades desses estudantes. No entanto, os resultados deste estudo apontaram que a Educação Inclusiva ainda não se efetivou por completo na escola do campo investigada, embora uma das professoras entrevistadas busca desenvolver um trabalho diferenciado com estes estudantes. Os dados evidenciam que é necessário um maior investimento por parte da esfera pública, tanto no que concerne à infraestrutura da escola, ao seu currículo. à formação inicial e continuada destes professores, como à acessibilidade destes estudantes, em suas múltiplas dimensões.

Considerando a complexidade do processo de inclusão, é necessário repensar o paradigma de escola do campo que temos, isto é, idealizada e construída para a homogeneidade e para o aluno padrão. Para reverter esse cenário, é urgente e necessária a mudança de atitude dos vários segmentos que se coadunam na educação, principalmente, dos professores, gestores e da própria instituição, que devem abandonar o conservadorismo de suas práticas, construindo uma educação que possa atender e responder às necessidades de todos os estudantes.

Nessa perspectiva, esta pesquisa pode dar contribuições significativas, visto que, nas falas dos professores, observamos situações veladas de preconceitos e de dicotomias entre os documentos 
oficiais e as práticas docentes desenvolvidas pelos professores investigados. Assim, com base em estigmas e estereótipos, percebemos que alguns destes professores ainda consideram a deficiência como sinônimo de incapacidade. O olhar de descrédito de alguns professores, nas potencialidades dos estudantes com deficiência poderá trazer implicações para o processo de mediação e, por consequência, na aprendizagem destes estudantes.

Além disso, os professores reclamam das lacunas em sua formação inicial, nos programas de formação continuada, e da falta de materiais que atendam às especificidades desses estudantes, embora afirmem que se esforçam em dar conta do seu papel. Entretanto, é visível que há, nos professores, uma preocupação em salvaguardar a imagem da escola ou isentar-se de responsabilidade no processo de inclusão destes estudantes com deficiência. Então, responsabilizam sempre as instituições e atores (gestores públicos, família) externos à escola. É importante destacar que, embora se reconheça as lacunas das políticas públicas, quanto ao suporte concreto e as condições efetivas de trabalho, não se dever isentar os atores do intramuros escolar, os professores, cujas práticas e atitudes precisam ser pensadas, refletidas e reorganizadas, pois são fundantes para a inclusão.

Assim, quando questionados sobre as práticas desenvolvidas com vistas à inclusão dos estudantes com deficiência, as respostas foram lacunares, apontando sempre para a falta de materiais e de oferta de formação e, por vezes, delegando a responsabilidade para a professora da SRM. Nessa perspectiva, se reconhece a adversidade das condições de trabalho, mas se entende e defende a necessidade de um maior protagonismo dos professores e, não só dessa escola, mas também dos formadores de professores, responsáveis pela formação inicial e continuada; uma mudança de cultura, no sentido de aprender a trabalhar de forma colaborativa, de transcender a reflexão e agir, sem colocar, sempre na mão do outro, a responsabilidade de sua formação e/ou de sua prática docente.

Pois, como afirma Macedo (2010), o professor que concebe a formação como um produto 'exterodeterminado', nega a sua própria condição de sujeito, de ser em formação. Precisamos entender que o contexto inclusivo exige a redefinição do papel do professor e nos dá clareza da provisoriedade da formação.

Além do exposto, no tocante à formação, apontado por todos os professores, acrescentamos também outras fragilidades que impactam no processo de inclusão, como a falta de acessibilidade, em suas várias dimensões (arquitetônica, atitudinal, aos materiais e recursos, a metodologias, dentre outras), o pouco apoio à implementação das políticas públicas, para que a Educação 
Inclusiva não se restrinja à inserção do estudante no ambiente escolar, mas que possa acolhê-lo, independentemente de suas limitações, para que tenham garantidos não só o direito de estar, mas também o de aprender. Em se tratando da Educação do Campo, em interface com a inclusão de estudantes com deficiência, isso requer um esforço maior para ser empreendido.

Para tanto, se faz urgente a construção e a implementação de políticas fundamentadas em valores humanos e sociais, na emancipação, na justiça, na equidade de oportunidades, na liberdade e no respeito à diversidade, visando à construção de uma educação que contenha, ao mesmo tempo, o caráter comum a todos e que sejam contempladas as particularidades, em respeito à realidade das vidas destas pessoas com deficiência que vivem e sobrevivem no/do campo.

\section{Referências}

ALMEIDA, M. da S. R. O que é deficiência intelectual ou atraso cognitivo. Instituto Inclusão Brasil, 2013. Disponível em: http://www.cursosavante.com.br/cursos/ curso526/conteudo7547.pdf. Acesso em: 10 de fevereiro de 2019.

ALVES-MAZZOTTI, A. J. O método nas ciências naturais e sociais: pesquisa quantitativa e qualitativa. 2. ed. São Paulo: Pioneira, 2002.

AZEVEdo, J. M. L. A Educação como Política Pública. 3. Ed., Campinas: Autores Associados, 2003.

BRASIL. Decreto $\mathrm{n}^{\circ}$ 6.949, de 25 de agosto de 2009. Presidência da República Casa Civil Subchefia para Assuntos Jurídicos. Disponível em: http://www.planalto.gov.br/ccivil03/ato2007-2010/2009/de creto/d6949.htm. Acesso em: 10 de fevereiro de 2019.

Decreto $n^{o}$ 7.612, de 17 de novembro de 2011. Disponível em: http://www.planalto.gov.br/ccivil03/Ato2011-2014/2011/Decreto/D7 612.htm . Acesso em: 10 de fevereiro de 2019.

Lei $\mathrm{n}^{\mathrm{o}}$ 13.146, de 6 de julho de 2015. Disponível em: http://www.planalto.gov.br/CCIVIL03/Ato2015-2018/2015/Lei/L13146.ht m. Acesso em: 22 de dezembro de 2018.

CALDART, R. S. Educação do Campo. Dicionário da Educação do Campo. 2.ed. Rio de Janeiro, São Paulo. 2012.p. 258 a 260.

CANDAU, V. M. F. Diferenças Culturais, Cotidiano Escolar e Práticas Pedagógicas. Currículo sem Fronteiras, Lisboa; Porto Alegre, v. 11, n. 2, p. 240- 255, jul./dez. 2011.

DINIZ, D.; PEREIRA, L. B.; SANTOS, W. R. dos. Deficiência, direitos humanos e justiça. 2009, p. $67 . \quad$ Disponível em: https://scholar.google.com.br/scholar?hl=ptBR\&as_sdt=0\%2C5\&q=conceito+de+defici\%C3\%AAn cia\&oq=\#d=gs_cit\&u=\%2Fscholar\%3Fq\%3Dinfo\%3A1EMG_xokhf4J\%3Ascholar.google.com\%2 F\%26output\%3Dcite\%26scirp\%3D0\%26hl\%3D pt-BR . Acesso em: 10 de fevereiro de 2019. 
DUARTE, R. Pesquisa qualitativa: reflexões sobre o trabalho de campo. Departamento de Educação da Pontifícia Universidade Católica do Rio de Janeiro. 2002. Disponível em: http://www.scielo.br/pdf/\%0d/cp/n115/a05n115.pdf. Acesso em: 10 de fevereiro de 2019.

FERREIRA, P. N. P.; PORTO, K. S. Práticas Pedagógicas desenvolvidas com alunos com deficiência: um estudo de caso em uma escola do campo de Feira de Santana - BA. Revista Brasileira de Educação do Campo, v. 5, p. e7913, 3 jul. 2020.

FRANCO, M. A. S. Pedagogia e Prática Docente. São Paulo: Cortez, 2012.

FREIRE, P. Pedagogia da autonomia: Saberes necessários à prática educativa. 53. ed. Rio de Janeiro: Paz e Terra, 2016, p. 28-40.

JOHNSON, B.; CHRISTENSEN, L. Educational research: quantitative, qualitative, and mixed approaches. Thousand Oaks: Sage, 2012.

MACEDO, R.S. Compreender/mediar a formação: o fundante da educação. Brasília: Liber Livro Editora, 2010. 252p.

MAIOR, I. História, conceito e tipos de deficiência. Portal do Governo do Estado de São Paulo. Disponível em: http://violenciaedeficiencia.sedpcd.sp.gov.br/pdf/textosap oio/texto1.pdf_. Acesso em: 10 de dezembro de 2018.

MARTINS, J. B.; TOLEDO, E. H. de. A atuação do professor diante do processo de inclusão e as contribuições de Vygotsky. Eixo Temático: Formação de Professores e Profissionalização Docente. 2009, p. 4129-4135. Disponível em: http://educere.bruc.com.br/arquivo/pdf2009/3298_1675.pd f. Acesso em: 10 de fevereiro de 2019.

MATOS, A. P. da S. Práticas pedagógicas para inclusão de estudantes com deficiência na educação superior: um estudo na UFRB. Salvador: 2015, p.103, 119. Disponível em: https://repositorio.ufba.br/ri/bitstream/ri/17728/1/ Disserta\%C3\%A7\% C3\%A3o\%20Aline\%20Pereira\%20da\%20Silva\%20Matos.p df. Acesso em: 10 de fevereiro de 2019.

MEDEIROS, A. C. C. de. Inclusão escolar: um novo olhar sobre o aluno incluso em uma escola municipal de São João d’Aliança-GO \% Brasília: 2015. Disponível em: http://bdm.unb.br/bitstream/10483/13649/1/2015AdrianaChavesCordeirodeMedeiros. pdf. Acesso em: 20 de dezembro de 2018.

MOLINA, M. C.; FREITAS, H. C. de A. Avanços e desafios na construção da Educação do Campo. Em Aberto. Brasília, v. 24, n. 85, p.20, abr. 2011. Disponível em: http://www.rbep.inep.gov.br/index.php/emaberto/article/viewFile/2493/ 2450. Data de acesso: 15 de dezembro de 2018.

MORAES, R.; GALIAZZI, M. C. Análise Textual Discursiva. 2. ed. Ijuí: UNIJUÍ, 2011.

MORATO, P. Mais ética, menos estética. Contributo para uma cultura da inclusão. Revista de Educação Especial e Reabilitação, v.10, n.1, p.7-11, 2003.

O GLOBO SOCIEDADE. Aumenta inclusão de alunos com deficiência, mas escolas não têm estrutura para recebê-los. Rio de Janeiro, 2017. Disponível em: https://oglobo.globo.com/sociedade/educacao/aumenta-inclusao-de-alunos-com-eficiencia-masescolas-nao-tem-estrutura-para-recebe-los-22348736. Acesso em: 10 de fevereiro de 2019.

PALMA, D. T. Escolas do campo e Atendimento Educacional Especializado em Sala de Recursos Multifuncional / Debora Teresa Palma - 2016. Disponível em: 
https://repositorio.unesp.br/bitstream/handle/11449/136453/palma_dt_me_arafcl.pdf?sequence=3\&i sAllowed= y Acesso em: 10 de fevereiro de 2019.

RIBEIRO, S. S. Estratégias pedagógicas para a permanência de estudantes surdos na Educação Superior. 2017. Dissertação (Mestrado) - Faculdade de Educação, Universidade Federal da Bahia, Salvador, 2017.

RIBEIRO, S. Lucas. Acessibilidade para a Inclusão na Escola: princípios e práticas. In: Sitientibus Revista da Universidade Estadual de Feira de Santana. Feira de Santana, n.44, p. 79-98, 2011

SANCHES, I.; TEODORO, A. Procurando indicadores de educação inclusiva: as práticas dos professores de apoio educativo Universidade Lusófona de Humanidades e Tecnologias, Portugal. Revista Portuguesa de Educação, 2007, 20(2), p. 105, 113 e 149 (C) 2007.

SANTOS, F. M. dos. Análise de conteúdo: a visão de Laurence Bardin. Resenha de: [BARDIN, L. Análise de conteúdo. Revista Eletrônica de Educação, v. 6, n. 1, mai. 2012. Resenhas. v.6, no. 1, p.383-387, mai. 2012.

SANTOS, A. O.; OLIVEIRA, G. S. de; JUNQUEIRA, A. M. R. Relações entre aprendizagem e desenvolvimento em Piaget e Vygotsky: o construtivismo em questão. Revista Itinerarius Reflectionis - UFG. Volume 10, nº 2, julho-dezembro 2014, Jataí-GO. Semestral. p. 18.

SASSAKI, R. K. Nada sobre nós, sem nós: Da integração à inclusão - Parte 2. Revista Nacional de Reabilitação, ano X, n. 58, set./out. 2007, p.20-30.

SILVA, P. B. da et al. A inclusão do estudante surdo no ensino superior: das percepções de estudantes surdos e seus professores às práticas de sala de aula. Estudo de caso. 2015, p. 19, Dissertação de Mestrado.

Recebido em: 17/06/2020

Aprovado em: 09/12/2020 